\title{
Auto-socioanálise: uma ferramenta a serviço da democratização da universidade? Retorno crítico sobre uma experiência pedagógica
}

\section{Resumo}

No âmbito deste artigo, estamos fazendo um retorno crítico sobre uma experiência pedagógica que consistiu em iniciar na autosocioanálise um público de estudantes recém chegados à universidade no contexto de um curso obrigatório de metodologia (L1, ciências da educação). Propomos aqui de testar pela análise sociológica a ideia de que a auto-socioanálise poderia constituir uma alavanca de ação pedagógica pertinente para favorecer a aculturação universitária dos estudantes e, portanto, a democratização da universidade.

\author{
Séverine Kakpo \\ Université Paris 8 Vincennes- \\ Saint-Denis - França \\ severinekakpo@gmail.com \\ Claire Lemêtre \\ Université Paris 8 Vincennes- \\ Saint-Denis - França \\ claire83140@gmail.com.fr
}

Palavras-chave: Auto-socioanálise. Estudantes. Socialização. Trabalho universitário. Desigualdades. Primeiros ciclos universitários.

\section{Para citar este artigo:}

KAKPO, Séverine; LEMÊTRE, Claire. Auto-socioanálise: uma ferramenta a serviço da democratização da universidade? Retorno crítico sobre uma experiência pedagógica. Revista Linhas. Florianópolis, v. 21, n. 45, p. 144-164, jan./abr. 2020. Título original L'auto-socioanalyse: un outil au service de la démocratisation universitaire? Retour critique sur une expérience pédagogique. Tradução: Fernando Coelho. 
Self-socioanalysis: a tool at the service of university democratisation? Critical feedback on a pedagogical experience

\begin{abstract}
This paper provides a critical insight on a learning experience which taught first-year students selfanalysis. This learning experience was part of a compulsory course in educational studies. We test the hypothesis according to which self-analysis is a meaningful learning process to favor transition from high school to the university environment (or to favor students' adaptation to mainstream educational and academic culture). If such is the case, teaching selfanalysis would definitely support the opening up of higher education.

Keywords: Self socio-analysis. Students. Socialization. Academic work. Inequalities. University undergraduate.
\end{abstract}


A auto-socioanálise, que pode ser definida como a auto-objetivação das próprias disposições e crenças sobre essas mesmas disposições (BOURDIEU, 2004) é provavelmente uma ferramenta pedagógica típica da sociologia. Nosso conhecimento nativo das práticas pedagógicas universitárias nos faz pensar que os alunos são regularmente convidados, durante sua formação, a fazer um retorno sobre si mesmos, com vistas a uma iniciação prática ao raciocínio sociológico. A auto-socioanálise é, sem dúvida, com menos frequência mobilizada com o objetivo mais específico de promover a aculturação de estudantes no mundo acadêmico. Esse é o sentido da experiência pedagógica que realizamos desde 2015 na Licenciatura 1 em ciências da educação na Universidade Paris 8, com um público formado principalmente por estudantes vindos de categorias populares.

Essa experiência faz parte de um curso obrigatório de metodologia de trabalho universitário, intitulado "Tornando-se um estudante na universidade", destinado a fornecer aos alunos de L1 as contribuições essenciais para sua adaptação ao mundo universitário (anotações, leitura de textos científicos, gestão do tempo na universidade, pesquisa documental, etc.). Partindo do princípio de que uma apropriação real desse conteúdo requer a implementação de um trabalho de autorreflexão, convidamos os alunos a produzir, na forma de um "balanço", uma auto-socioanálise de sua trajetória escolar e de sua experiência inicial na universidade. Este trabalho se faz com um acompanhamento cuidadoso por instruções escritas, fornecendo-lhes questionamentos problematizados para cada um dos temas a serem abordados (meio social de origem, trajetória escolar, escolha da universidade, aprendizado na universidade, relação com o tempo etc.) Para alimentá-lo, pedimos aos alunos que mantenham regularmente um diário de bordo de sua entrada na universidade. Reunidos em um dossiê de pelo menos quinze páginas, o "balanço" e o "diário" servem de base para a avaliação deste ensino, que é creditado com seis ECTS (European Credits Transfer System). Se certas sessões de curso são baseadas na leitura de um texto sociológico, é principalmente fora deste ensino que os alunos são introduzidos à sociologia, dentro da estrutura de um EC (Element Constitutif) obrigatório de "introdução à sociologia da educação" pelo qual também somos responsáveis. Centrado na noção de "socialização", este curso aborda as 
diferentes dimensões deste processo e apresenta aos alunos, por meio de referências e textos variados, a desconstrução sociológica do senso comum.

No âmbito deste artigo, desejamos fazer um retorno crítico sobre essa experiência pedagógica, tentando colocar à prova pela análise sociológica a ideia segundo a qual a auto-socioanálise poderia constituir uma ferramenta pedagógica de democratização universitária. O corpus aqui mobilizado consiste em sessenta e cinco dossiês coletados durante o primeiro semestre do ano universitário de 2016-2017, e cujo número de páginas varia entre seis e quarenta. Com essa abordagem, alinhada com vários trabalhos anteriores (CHAPOULIE, 2000; SOULIE \& GADEA, 2000; SOULIE, 2002; JOUNIN, 2014), pretendemos contribuir com a construção de um espaço coletivo de reflexividade sociológica em torno das práticas de ensino no curso superior. Exercer e tornar visível nossa reflexividade sociológica sobre o assunto parece essencial em um contexto marcado pelo aumento da força de especialistas em "pedagogia universitária”, que tendem a designar os acadêmicos como "profanos" da pedagogia e a construir o problema do "fracasso " na universidade como sendo principalmente o de sua “ incompetência pedagógica " (GARCIA, 2008).

\section{Interrogar o dispositivo pedagógico a priori}

Antes de tentar entender como os alunos se apropriam do trabalho solicitado, um exercício inicial se impõe: o de questionar a priori o dispositivo e, especialmente, as crenças que estão na base dele.

\section{Um espaço pedagógico dominado, porém, desejável}

A sociologia de um dispositivo pedagógico não pode prescindir da análise das lógicas de ação dos indivíduos que o usam (MUEL DREYFUS, 1983). Então, começaremos por nos submeter a um trabalho de auto-objetivação. Mais precisamente, tentaremos lançar luz sobre as forças motrizes por trás de nosso investimento em um curso não disciplinar para estudantes L1, um espaço pedagógico dominado. 
O fato de nos encarregarmos desse tipo de curso pode ser analisado como um dos efeitos da divisão estatutária, de gênero e social do campo universitário (BOURDIEU, 1984 a). Somos professoras-pesquisadoras em início de carreira, mulheres, além de mães de família, e não apresentamos o perfil de herdeiras, sendo respectivamente de origem artesanal e agrícola. Apesar das atividades regulares de pesquisa e publicação, nossos perfis dificilmente atendem aos critérios de "excelência" acadêmica: nós não somos de uma École Normale Supérieure, não participamos de nenhum projeto "ANR", não somos inscritas em redes internacionais etc. Portanto, estamos no "fundo" do topo do campo universitário, ou seja, as "dominadas relativas" da instituição. Portanto, pode parecer óbvio que nos encarregamos do que parece ser uma forma de "trabalho sujo" em um universo onde o prestígio simbólico se encontra tradicionalmente no lado da pesquisa (CHARLES \& GADEA, 2000) ou do ensino para níveis altos de formação.

No entanto, esta leitura não é completamente satisfatória. De fato, nosso investimento se mostra, apesar de tudo, no universo hierarquizado do mundo universitário. Somos, por assim dizer, "qualificados demais" para esse tipo de curso geralmente delegado aos não titulares. Para conseguir o encargo, tivemos que despojar as prerrogativas pedagógicas de um “velho" doutor sem perspectiva de posição, que há vários anos era responsável por todas as ECs metodológicas em nosso departamento. Nossa abordagem também suscitou a perplexidade de certos colegas, que ficaram surpresos ao ver "titulares" se encarregarem dos cursos e ficaram preocupados com as possíveis consequências negativas dessa escolha no próximo "diálogo orçamentário".

Por que estamos tão ansiosos para ocupar esse espaço onde não estamos inteiramente em nosso lugar? Principalmente porque o "trabalho sujo" também nos parece um "belo trabalho". Tendo conhecido uma trajetória de mobilidade social ascendente, além de estar sempre inscritas em um processo de aculturação profissional no mundo universitário, temos uma vontade sincera de transmitir aos alunos provenientes da massificação as "chaves do sistema" e, portanto, de implementar uma pedagogia racional (BOURDIEU, \& PASSERON, 1964).

Enfim, em outro registro, esse espaço relegado também nos apareceu como um espaço a ser conquistado, no qual as restrições são fracas e onde a criatividade pedagógica pode ser expressa com mais liberdade; não se trata de transmitir conteúdo 
disciplinar, nem de pré-profissionalizar. Assim, esse espaço acabou sendo um "curso do mato", no âmbito do qual foi possível experimentar outras formas pedagógicas e outras formas de trabalhar, especialmente em dupla.

Por fim, é necessário desconstruir a aparente fraqueza do nosso "senso de posicionamento" (BOURDIEU, 1984 b). De fato, a crise de atratividade em nosso mestrado de pesquisa e, mais amplamente, em mestrados universitários em ciências humanas e sociais ocorre de modo que a licenciatura pode legitimamente aparecer nesse contexto como um horizonte desejável. No primeiro ano, ensinamos aos alunos que realmente apresentam, para uma pequena parte deles, um perfil socio-escolar que não encontramos no mestrado ou de uma maneira completamente excepcional: alunos que têm o baccalauréat geral, na hora escolar, de origens relativamente dotadas de capital cultural etc. Os "bons" alunos estão, portanto, mais no "fundo" do que no "topo" do currículo.

Agora que as fontes de nosso investimento foram esclarecidas, nós nos propomos a questionar as crenças na base de nosso dispositivo.

\section{As supostas virtudes pedagógicas da auto-socioanálise}

O engajamento pedagógico, como qualquer forma de engajamento, é baseado em crenças. As virtudes que atribuímos à auto-socioanálise referem-se a uma função clássica da sociologia crítica. De acordo com Pierre Bourdieu (1984 b), a sociologia teria realmente o poder de "desmaterializar" o mundo social. Desnaturalizaria a necessidade, mostrando que esta é o produto das relações sociais. O papel do sociólogo seria, portanto, gradualmente levar os "agentes" a objetivar sua posição, entender seu "habitus" e, se necessário, "atribuir seu sofrimento a causas sociais". A entrevista sociológica, concebida por Bourdieu como uma forma de "auto-análise assistida" (1991), seria inclusive uma ferramenta privilegiada para a emancipação social.

Experimentando outra forma de "auto-socioanálise assistida", buscamos mais precisamente libertar os alunos de uma leitura naturalizante de sua trajetória e desconstruir suas representações de meritocracia escolar (BOURDIEU \& PASSERON, 1964, 1970). O desafio é fazer com que compreendam que as possíveis dificuldades que 
eles encontram ao ingressar na universidade ou que encontraram anteriormente não decorrem de características estritamente individuais, mas de um contexto histórico e social e provisões adquiridas durante a socialização. A auto-socioanálise assim realizada deveria, portanto, levá-los a concluir que "não nascemos estudantes".

Nossa abordagem também visa logicamente ajudar nossos ingressantes a "se tornarem estudantes". Segundo Bourdieu (BOURDIEU \& WACQUANT, 1992), a apreensão dos determinismos sociais abre caminho para um possível "trabalho de si mesmo", consistindo em tentar "inibir" ou "submeter" suas disposições pelo efeito de uma vontade e um esforço racionais. É nesse tipo de "transformação de si" que queremos iniciar os alunos. Para dar um exemplo concreto, pensamos que os alunos que estão mais afastados das expectativas da universidade em termos de leitura poderiam ser levados a abordar o trabalho solicitado pelos professores de maneira diferente, se conseguissem entender que esses pré-requisitos estão localizados socialmente e que o relacionamento deles com a leitura resulta de sua socialização anterior. Com base nessa análise, eles poderiam então racionalmente apreender as injunções para ler que lhes são formuladas como uma possibilidade que lhes é oferecida de se submeter a formas de treinamento metódico e intensivo, suscetíveis de vir progressivamente transformar suas disposições.

Como sociólogos, não abordamos essa experiência de forma tão ingênua. Logo de início somos questionados sobre o mérito dessas crenças pedagógicas.

\section{Crenças tecidas em ilusões?}

Nossas perguntas primeiro se concentraram na natureza fundamentalmente acadêmica do trabalho esperado. A auto-socioanálise pode ter alguma virtude emancipatória se não for um trabalho voluntário? Em vez de um verdadeiro processo de introspecção, não existe o risco de ver essencialmente no desempenho, estratégias de auto-apresentação? O formato do exercício e o período em que ele é registrado são compatíveis com a implementação de tal abordagem? Podemos fazer nossa autosocioanálise em poucas páginas? E isso, após um único semestre de iniciação à sociologia, no contexto de uma licença multidisciplinar, o que há mais? Em suma, o que há em comum entre o exercício a que sujeitamos nossos alunos e o longo e voluntário trabalho 
de auto-análise liderado por Younes Amrani, sob a liderança de Stéphane Beaud em Pays de malheur! (2005), que constitui um modelo do gênero?

Também nos perguntamos sobre os pressupostos sociais do trabalho esperado. $O$ acesso a essa reflexividade não é de fato neutro. Os trabalhos realizados em campo na sociologia da cultura mostram que a escrita autobiográfica é uma prática cultural pouco frequente, essencialmente feminina e marcada socialmente (DONNAT, 2010). Também sabemos que nem todos têm a mesma propensão a "falar de si mesmos" e não têm "algo a dizer sobre/de si mesmos" (POLIACK, 2002). A capacidade de "narrar a sua vida" é, portanto, mais difundida nas classes médias e altas, onde a psicologia e a psicanálise têm sido mais difundidas e onde o sentimento de sua singularidade é mais evidente. Realizar tal trabalho também implica descentralizar o "eu íntimo". Entretanto, essas disposições de "secundarização" são desigualmente compartilhadas de acordo com o meio social (BAUTIER, 2005).

Enfim, esperar que os estudantes se dediquem a um trabalho de transformação de suas disposições não significa ceder a uma nova forma de ilusão meritocrática? Isso não significa retomar a concepção ilusória de um sujeito consciente capaz de dominar seu destino (DARMON, 2006)? As disposições, em particular as adquiridas durante a socialização primária, apresentam por definição uma forte inércia, uma grande capacidade de resistência às mudanças (BOURDIEU, 1980). Ser capaz de se transformar exige condições que não cremos que sejam todas satisfeitas, nossos alunos sendo educados em uma instituição que deve ser lembrada pelo fraco poder socializante, comparada a outras instituições, principalmente os cursos preparatórios (DARMON, 2013). Mesmo que a "vontade" possa ser sociologicamente vista como um exemplo real de socialização, devemos ter cuidado para não esquecer que essa "vontade" é sempre socializada e, portanto, socialmente localizada (DARMON, 2003, 2006).

\section{Interrogar as produções dos alunos}

Agora vamos tentar entender o que os alunos "fazem" com o exercício e o que o exercício "parece" fazer com eles. O uso do modalizador é importante. Os estudantes respondem a uma ordem institucional que os convoca implicitamente a atestar uma 
conversão ao mundo universitário e à sociologia. Portanto, nos limitaremos a falar aqui de efeitos declarados ou supostos.

\section{Objetivar seu ambiente social original}

Primeiro, focaremos em entender como os alunos se apropriam da primeira parte do trabalho, que consistia em objetivar seu ambiente social original. Mais precisamente, os alunos tiveram que relatar a trajetória social de seus pais, identificar o capital familiar ou, sendo o caso, destacar o baixo grau de legitimidade dos recursos disponíveis, identificar as principais características de seu universo de socialização e destacar a conivência ou distância do mundo escolar que caracteriza esse universo.

A análise do corpus mostra que os alunos realizam o exercício de maneira muito desigual, de acordo com seu perfil social. De fato, aqueles que conseguem construir uma visão sociologicamente distanciada de sua família costumam ter saído de um ambiente relativamente bem-dotado em termos de recursos culturais, seus pais tendo estudado e/ou possuindo qualificações significativas e/ou até tendo capital academicamente rentável (um relatório redigido "feliz", por exemplo). Esses alunos costumam dar um relatório preciso da extração social de seus pais, assim como de sua trajetória social:

Meus avós vêm de uma meio popular e meus pais na verdade não saíram, meu pai ainda é operário e minha mãe empregada, no entanto eles subiram alguns degraus nas classes mais baixas porque têm um emprego estável e no caso de minha mãe, uma profissão que a coloca em contato com muita escrita, com também muita gente, hoje ela tem muita responsabilidade, algo que, na família, tem sido visto muito pouco em gerações anteriores. (... ) Meu pai é o caçula de cinco irmãos, ele teve acesso aos mesmos estabelecimentos de ensino, os mesmos recursos que esses irmãos e irmãs, mas eu noto que minhas tias tiveram uma carreira mais longa que seus irmãos: são gerentes ou empregados qualificados enquanto os irmãos são operários, meu pai me disse que o pai deles trabalhava mais com ele e meu tio e que na família o víamos com um olho melhor, quando um homem favoreceu o trabalho manual para um comércio que exigia uma "perda de tempo" nos estudos. (Maud, bac S, pai da construção civil, mãe secretária). 
Alguns, em particular, não hesitam em mobilizar com muita precisão as ferramentas apresentadas na aula, como os PCS:

Meus pais estão nas categorias $372 \mathrm{c}$ e $421 \mathrm{~b}$. Meu pai, responsável por recursos humanos, formou-se no CAP, BEP e BAC Pro "agente administrativo e de informática, opção de contabilidade". Ele retomou os estudos para receber o diploma "Equipe de Recursos Humanos". (...) Minha mãe é professora escolar e mestre formadora. Ela se formou com um Bac+4 e um Certificat d'Aptitude aux Fonctions d'Instituteur ou de Professeur des Écoles Maître Formateur (CAFIPEMF). (Elodie, bac L)

Eles também analisam em detalhes a estrutura do capital familiar. Para mostrar que ela sempre esteve imersa em um ambiente familiar em que a escrita era significativa, Mégane evoca, por exemplo, as práticas de leitura de seu pai, que é vendedor de carros, mas também filho de uma antiga "redatora-chefe" da imprensa:

Ele é (...) apaixonado por leitura, lê absolutamente tudo, sejam romances policiais, "A Equipe", "Le Point", estórias em quadrinhos e, às vezes, revistas femininas de minha mãe. Nem um único dia, eu o vejo sem ler alguma coisa, e é graças a todas as suas leituras que ele sabe muitas coisas. (Mégane, bac S, mãe conselheira de clientela, setor bancário).

Alguns estudantes também trabalham, com óbvia boa vontade cultural, para elaborar verdadeiros inventários de capital:

Três bibliotecas, obviamente com muitos livros, instrumentos musicais (dois violões e um piano), medalhas (competição de esportes ou de xadrez vencida por minha irmã ou por mim) ou números de peito em corridas a pé de que meu pai pode participar, minha irmã também possui um prêmio literário concedido pelo Conselho Geral de la Seine-Saint-Denis. (... ) Uma coleção de jornais, sendo uma de pelo menos 100 anos atrás (...). (Algumas) joias, como um relógio de bolso com mais de 50 anos e brincos de mais de 70 anos dados à minha mãe pelo pai ou pela sua tia-avó (...). (Elodie, bac L, pai responsável pelos recursos humanos, mãe mestre formadora Espé).

Esses alunos então realizam análises relativamente elaboradas das características socializantes de seu ambiente familiar e da relação que elas têm com as normas escolares. Para isso remobilizam de maneira relevante as contribuições dos textos trabalhados no âmbito do curso: 
Aprendo e começo a incorporar as maneiras de analisar os sociólogos. (...) Eu joguei jogos especialmente o Scrabble com minha mãe. Isso me faz pensar em Daniel Thin quando ele disse que as famílias populares brincam com seus filhos para relaxar, se divertir e não necessariamente para continuar o aprendizado escolar em casa. É verdade que o Scrabble é um jogo bem característico das famílias das classes médias e altas. (Pauline, bac S, pai formador em padaria, mãe secretária administrativa).

Enquanto os alunos mais privilegiados se prestam ao exercício com relativa facilidade, aqueles que vêm de famílias mais privadas de recursos legítimos parecem ter mais dificuldade em se apropriar deles. Em seus dossiês, as lógicas de socialização da família são muito pouco descritas e menos ainda analisadas. A distância entre o mundo escolar de seu local de origem nunca é documentada com precisão, embora o curso lhes fornecesse muitas ferramentas capazes de ajudá-los a desconstruir a ideia de um "déficit" cultural consubstancial às famílias de bairros populares e ter acesso a um entendimento mais relacional das relações sociais de classe. Porém, esses estudantes não a compreendem e desenvolvem uma leitura essencialmente "deficitária" do seu ambiente familiar:

Meus pais não têm cultura legítima na França, praticamente nunca estudaram e não têm lazer. Somos uma família da classe trabalhadora. (Firuze, bac pro gestão/administração, pai empregado de catering, mãe dona de casa).

Esses estudantes, assim, permanecem em grande parte prisioneiros das hierarquias culturais que internalizaram e que tendem a "invisibilizar" todas as outras práticas, desde que não sejam claramente apresentadas como legítimas.

\section{Desnaturalizar sua trajetória escolar}

Como continuação do trabalho realizado sobre seu ambiente de origem, os alunos tiveram que retornar à sua trajetória escolar. Nossas instruções os convidaram especificamente a mobilizar as contribuições de seus cursos para refletir sobre os vínculos entre socialização familiar e socialização escolar, sobre o contexto socioeducativo em que foram educados, assim como sobre a influência de seus pares em 
sua trajetória escolar. Novamente, ressalta da análise que os alunos cumpriram o trabalho esperado através de formas bem diversas.

Aqueles que até agora tiveram escolaridades bem-sucedidas ou pouco marcadas pelas "dificuldades", quase sempre conseguem - mesmo que permaneçam formas de essencialização - recontextualizar sua trajetória escolar. Então Marjorie decide analisar as fontes familiares da "boa vontade" escolar que sempre a animou:

Meus pais incutiram em mim os valores da escola (...) Desde que aprendi a falar e entender o que me dizem, pelo menos que eu me lembre, meu pai sempre me disse esta frase "A escola é importante; Você não pode imaginar a que ponto é difícil acordar de manhã para um trabalho que você não gosta de verdade." (Marjorie, bac STMG, pai, administrador de rede, mãe, dona de casa).

Esses alunos também costumam enfatizar a importância dos investimentos pedagógicos familiares:

Meus pais sempre estavam bastante envolvidos com a minha escolaridade e de minha irmã, eles estavam presentes na hora dos nossos deveres de casa, para nos ensinar coisas quando podiam, e também, o que me permitiu de ir às vezes mais rápido do que outros alunos. (Maud, titular de um bac S, pai operário da construção civil, mãe, secretária).

Outros destacam o papel socializador desempenhado pelas "pessoas de recursos" de seu círculo mais amplo:

Meus pais sabem pouco sobre a escola. (... Felizmente, temos uma vizinha com um nível de bac ES+2 que realmente me ajudou muito desde o PC até o ensino médio (lycée) para os deveres de casa e revisões. Graças a ela, meu francês melhorou muito e eu fui bem. (Nora, bac S, pai operário em invalidez, mãe, dona de casa).

Os alunos que se sentem mais confortáveis com esse exercício de distanciamento não hesitam em desnaturalizar a trajetória educacional, geralmente menos bem-sucedida, de outros membros da família. É o caso de Pauline, que desenvolve, por exemplo, uma análise em termos de disposições socialmente construídas para esclarecer a relação com a escola de seu irmão: 
Talvez, se minha irmã e eu desenvolvemos uma relação mais próxima com a escolaridade, é porque o piano é mais escolar que o judô. De fato, nós dois tivemos aulas no conservatório e, para estudar piano, como para outros instrumentos, seguimos lições teóricas (...). Também fazemos exames no final de cada ciclo (...). Esses exames, como o certificado no final do colégio ou o bac no final do ensino médio (lycée), fortalecem o lado escolar. Também temos todos os anos o que chamamos de interlúdio. É como uma audição durante a qual tocamos e os professores nos dão nota (...). Talvez seja por essa razão que minha irmã e eu compilamos este relatório sobre escolaridade, enquanto nosso irmão o desenvolveu um pouco menos (Pauline, bac S, pai formador em padarias, mãe, secretária administrativa).

Por outro lado, alguns estudantes não operam nenhuma forma de desnaturalização de sua trajetória acadêmica. Eles são relativamente pouco numerosos (menos de uma dúzia) porque, na maioria das vezes, os alunos destacam a influência das expectativas dos pais em sua trajetória. Esses estudantes, no entanto, têm características comuns: metade deles provém de uma faixa profissional e nenhum possui um bac geral. Eles conheceram uma trajetória escolar marcada por "dificuldades" e às vezes repetiram de ano. Seus pais também têm em comum que eles têm pouca ou nenhuma formação completa.

Voltando à sua trajetória, esses alunos atribuem suas dificuldades a características psicológicas individuais. As análises - muitas vezes resumidas - que eles desenvolvem sobre o meio social de sua origem nunca são remobilizadas para esclarecer sua escolaridade. Os elementos que eles foram convidados a desenvolver em relação ao contexto de sua escolaridade não são reinvestidos (tipo de estabelecimentos frequentados, reputação, clima escolar, influência do grupo de pares etc.). Em resumo, esses alunos persistem em ser considerados apenas "contadores" de seu percurso escolar. Titular de um bac profissional "Serviço de Acompanhamento em Cuidados Pessoais", Cindy se descreve, por exemplo, como uma estudante que sempre apresentou "dificuldades de atenção" e "compreensão". Da mesma forma, a Hichem usa uma explicação totalmente descontextualizada para explicar a queda gradual de seus resultados ao ingressar na faculdade: 
Pouco a pouco, cada uma das minhas médias foi se deteriorando (...). Faltava-me concentração. (Hichem, bac pro eletrotécnica, pai agente funerário aposentado, mãe, dona de casa).

O fato de não encontrarmos no corpus exemplos de alunos que consigam contextualizar sua trajetória de alunos rotulados como "em dificuldade" levanta questões fortes quanto à capacidade do nosso dispositivo de "desfatalizar". Tal como está, este último parece incapaz de desalojar representações individualizadas fortemente ancoradas nesses estudantes, que, como se vê, estão longe de se divertir em uma suposta cultura de "desculpa sociológica" (LAHIRE, 2016).

\section{Observe seus primeiros passos na universidade}

Os estudantes afinal tinham que analisar sua socialização inicial na universidade. Questionar isso é, sem dúvida, um exercício particularmente exigente. No final de um primeiro semestre passado na universidade, estes ainda não têm uma visão do todo e estão provavelmente envolvidos demais para conseguir adotar um ponto de vista distanciado, e ainda sociológico.

As passagens do dossiê que tratam mais particularmente da questão do tempo mostram um baixo grau de reflexividade típico dos desenvolvimentos que os estudantes geralmente dedicam aos seus "primeiros passos" na universidade. Observe que esperávamos que eles analisassem sua relação com o tempo, com base principalmente na leitura de dois textos trabalhados como parte do curso de metodologia. O primeiro é um artigo de Stéphane Beaud intitulado "Le temps élastique" (1997), que analisa a experiência universitária e a relação com o tempo de "jovens de cidade". O segundo é um texto de Muriel Darmon, que trata do tempo nos cursos preparatórios (2013). Esses dois apoios convidavam os alunos a refletir sobre o caráter fracamente estruturado da universidade enquanto instituição educacional, bem como sobre suas disposições temporais. Em um objetivo mais diretamente prático, fizemos com que experimentassem diferentes ferramentas de gerenciamento de tempo (criação de um planejamento semanal, um retro-planejamento semestral etc.). 
O estudo dos dossiês mostra que os alunos mostram uma fraca reflexividade sobre essas questões, limitando-se com mais freqüência ao relato dos testes temporais com os quais são confrontados desde a entrada na universidade:

No ensino médio, as aulas eram lições de uma ou duas horas no máximo, ficar três horas na sala de aula para mim é um sofrimento, as aulas passam devagar (Chanel, bac ST2S, situação profissional dos pais não especificada, não graduados).

Da mesma forma, suas dificuldades organizacionais raramente são pensadas em termos de arranjos socialmente construídos. Em vez de dar suporte à reflexividade, o diário de bordo se torna, para muitos, uma crônica simples de sua incompatibilidade temporal:

Eu tinha planejado trabalhar, revisar, ter um fim de semana estudioso, mas, em vez disso, passei o fim de semana saindo com meus amigos, dormindo, comendo, assistindo séries. Em uma palavra, eu fiz tudo, exceto o trabalho. A pior parte é que escrevo meu diário semanal enquanto assisto a uma série e como batatas fritas. (Lucia, bac proadministração, pai, agente territorial, mãe, agente de manutenção).

O trabalho realizado pela maioria dos estudantes não parece, portanto, abrir caminho para um "trabalho de si mesmo" que envolveria algo que não seja um trabalho do tipo gerencial, sustentado por uma concepção dessocializada do indivíduo e da sua "vontade". Tantos desafios pessoais pelos quais podemos assumir que eles terão dificuldade em produzir os efeitos esperados para os alunos cujos arranjos iniciais são os menos programáticos:

Eu já havia feito um cronograma com revisões, momentos de relaxamento, sono, lazer, mas o tempo dedicado às revisões era muito baixo (apenas 3 horas por semana) e não podia realizar isso completamente. Foi, portanto, durante (esta) sessão que pude criar um cronograma mais adequado para revisões, arquivos etc. Infelizmente, eu não sabia como dominar esse cronograma adequadamente por um longo tempo e me vi fazendo revisões por dias inteiros e às vezes nem tanto, especialmente quando eu tinha fins de semana prolongados. (Aïcha, bac L, pai trabalhador, mãe assistente materna). 
Poucos estudantes (menos de uma dúzia) conseguem desenvolver um ponto de vista reflexivo real em sua relação com o tempo. Eles quase sempre têm o perfil de bons alunos do ensino médio, obtendo um bac geral com honras e geralmente vêm de famílias com formação acadêmica ou cultural relativamente boa. Uma noite, quando acaba de responder por escrito a perguntas relacionadas ao artigo de Stéphane Beaud, Mégane se pergunta em seu diário de bordo, por exemplo, sobre seu tempo. Ela tenta explicar suas fracas disposições ascéticas pela descontinuidade que ela percebe entre a universidade e seu universo familiar, seus pais tendo ou não frequentado a universidade:

À noite, li o texto e respondi à pergunta que nosso professor de "tornar-se estudante" na universidade" nos havia feito. Esse texto (...) me fez pensar muito e, quando o li, a impressão de me encontrar em certos pontos: como eles, acho difícil me concentrar quando estou em casa, sempre tenho mais algumas coisas "importantes" para fazer fora ou em casa com minha família; Tenho duas vidas muito distintas: em casa e na universidade. (...) Além disso, não falo muito sobre universidade em casa. Meus pais me fazem algumas perguntas, exceto a pergunta usual "O seu dia correu bem? "Eles estão muito interessados na minha educação e estão muito orgulhosos de mim, tenho certeza. (...) Mas diremos que, quando todos nos encontramos, conversamos mais sobre outras coisas, como falar sobre a educação do meu irmão (na $6^{a}$ série) e da minha irmã mais nova (Mégane, bac ES, pai vendedor de carros, mãe consultora de atendimento ao cliente no setor bancário).

A leitura do artigo em particular a levou a pensar com muito cuidado sobre a influência ambivalente de suas relações amistosas em seu ascetismo acadêmico:

Também me encontrei neste texto porque eu também, com meus amigos, incentivo e motivo a ir à aula. Eu tenho uma namorada no "BTS de gerente assistente" que acorda todas as manhãs no mesmo horário que eu porque ela também tem muito transporte e todas as manhãs nós ligamos ou enviamos uma pequena mensagem para nos motivar. E essa intenção, por menor que seja, realmente motiva. (...) Isso também me fez pensar por que meus amigos e eu estamos muito motivados para os nossos estudos (...). Do ponto de vista externo, somos paradoxalmente motivados, queremos a todo custo que o outro seja bem-sucedido, mas não mudamos nossos hábitos (passeios etc.) quando se aproxima um exame. 
A adoção desse "olhar externo" nos parece abrir caminho para um possível "trabalho de si mesmo" para os estudantes que, como Mégane, por melhores que sejam, têm obviamente transformações para operar para se aculturar na universidade. Esse trabalho conduzido sobre si mesmos nos parece próximo de uma forma de trabalho racional que provavelmente transformará as disposições. Após a leitura do texto de Stéphane Beaud, por exemplo, Mégane decide continuar com suas disposições e as características do contexto familiar em que evolui:

Eu implementei estratégias para aproveitar ao máximo meu tempo. Minha obsessão era ter que trabalhar todas as noites em casa e não conseguir tirar meu nariz dos cadernos. De repente, comecei a trabalhar no transporte, faço entre 3 e 4 horas de transporte por dia, então, decidi transformar essa restrição em um ativo, com o objetivo de voltar para casa com menos trabalho para fazer.

Em sua avaliação, ela fala sobre as transformações que pensa ter feito:

Desde que vim para a universidade, meu método de trabalho evoluiu bastante. Você poderia dizer que no ensino fundamental e médio eu realmente não tinha um, eu me baseava em minhas habilidades, revisava quando queria e chegava no controle dizendo para mim mesma "Vai ou racha" (como os alunos da investigação de Stéphane Beaud). No início do semestre, eu estava um pouco perdida (...). Com o tempo, me organizei. Para começar, faço meu tempo lucrativo lendo todos os textos no transporte. Então eu me proponho objetivos a cada semana, tento trabalhar quando não há ninguém em casa ou na biblioteca para me concentrar (...). Ainda tenho problemas para revisar se não tenho dever de casa, mas sinto que estou ficando cada vez melhor.

Este exemplo sugere que a implementação efetiva desse "trabalho de si mesmo" está, portanto, intimamente ligada à adoção de uma postura reflexiva, ansiosa por desnaturalizar as dificuldades encontradas, para entender sua origem, mas que também depende de arranjos previamente construídos. Mesmo se declarar o contrário, podemos assumir que os arranjos programáticos já estavam presentes em Mégane e apenas pediram, por assim dizer, "universidade". A identificação declarada desses estudantes com os "jovens da cidade" investigada por Stéphane Beaud é, portanto, basicamente relativa. 
Se a sociologia desnaturaliza, também desencanta, inevitavelmente. Analisar o trabalho produzido pelos alunos acabou sendo um exercício desencantador, para dizer o mínimo. O acesso a uma forma de auto reflexividade sociológica está longe de ser óbvio para todos os alunos. Finalmente, são aqueles que são os principais alvos do sistema educacional que mais se esforçam para construir uma visão distante de sua formação social e sua trajetória educacional: estudantes de famílias mais distantes do mundo escolar e / ou aqueles que tiveram as trajetórias educacionais mais pontuadas com "dificuldades".

Pode-se pensar que esses estudantes acham difícil se apropriar do exercício, porque são os menos preparados para enfrentar as demandas de um trabalho universitário exigente, mesmo que seja autorreflexivo. Se essa explicação for necessária, ela não deve se limitar a ela e também questionar a natureza do exercício esperado. Destacar posições sociais desvalorizadas, práticas culturais ilegítimas, lógicas socializantes que dificilmente se adaptam às lógicas dominantes, distanciando-se de vereditos negativos da escola, analisando as dificuldades de ingressar no mundo acadêmico é, sem dúvida, um exercício mais difícil do que o 'reverter.

Essa constatação, portanto, questiona a relevância dos critérios que usamos para avaliar o trabalho dos alunos. Esses eram de fato os mesmos para todos, embora o exercício provavelmente não seja imposto a todos da mesma maneira. Não seria aconselhável recompensar não o resultado a que os estudantes chegam, mas o progresso feito? Isso envolveria repensar a avaliação deste trabalho, uma tarefa inerentemente complexa por natureza quando se trata de avaliar produções que envolvem a "pessoa".

As análises extraídas do uso do material também levantam questões sobre os efeitos "colaterais" que o dispositivo poderia produzir. Que sentido faz para produzir um trabalho tão pessoal, se não for acompanhado por qualquer forma de reflexividade sociológica? Nessas condições, o exercício não corre o risco de se impor como uma forma de violência simbólica nos estudantes que acabaram de cruzar o limiar da universidade e se veem obrigados a declinar por assim dizer seu "número" social e / ou apresentar seu 
registro "escolar"? Esses estudantes não podem, assim, ser levados a internalizar ainda mais sua posição como social e / ou acadêmico "dominado" e a se sentirem sempre mais responsáveis pelas dificuldades que encontram em se tornarem "empreendedores de si mesmos" (EHRENBERG, 1998)?

Por outro lado, não são estudantes de famílias com as melhores doações acadêmicas ou culturais e / ou estudantes com as carreiras acadêmicas mais ricas os grandes "vencedores" do exercício? Eles se prestaram a um trabalho gratificante, o que pode levá-los a aproveitar suas vantagens de maneira mais racional e a criar mais seguro social no processo. Eles também se beneficiaram de uma iniciação prática à sociologia, que se poderia pensar que dará frutos pelo resto do curso de treinamento.

Além desses problemáticos "efeitos colaterais", outros aparecem ao ler os dossiês, o que nos permite qualificar um pouco esse achado relativamente grave.

Mesmo que todos enfatizem a dificuldade de enviá-lo no início, muitos estudantes dentre os mais distantes dos requisitos da universidade apontam na conclusão de seu dossiê os "benefícios" do trabalho de redação diário e restrito que constitui o diário de bordo. Esse treinamento regular, imposto e estruturado, permitiu visivelmente a alguns alunos desenvolver disposições para regularidade. Ir para o final deste trabalho de um semestre também parece ter tido efeitos simbólicos significativos sobre eles. Eles costumam dizer que nunca escreveram tanto ou gostaram de escrever pela primeira vez.

No final, o material coletado também se mostrou um valioso objeto de conhecimento para os professores que somos. Descobrimos praticamente o "lado avesso" de nossas salas de aula. Ao nos fornecer informações precisas sobre as condições materiais e morais da vida dos alunos, sua relação com a universidade e o conteúdo do conhecimento transmitido, ou sobre o peso das expectativas dos pais que pesam sobre eles, etc., esses dossiês permitem: conhecer melhor nossos alunos e entender melhor as "dificuldades" encontradas pelos mais "frágeis". Este trabalho reforçou nossa crença de que a universidade deveria se dar os meios para recebê-los, em vez de tentar bloquear seu acesso. 
Por mais desencantador que seja, esse retorno crítico não nos leva a abandonar a auto-socioanálise como ferramenta educacional, mas nos convida a pensar em novas maneiras de acompanhá-lo, na perspectiva de poder guiar mais de perto os estudantes menos dispostos a ter sucesso neste trabalho no caminho exigente, mas que, no entanto, permanece, a nosso ver, potencialmente emancipatório que eles precisam seguir.

\section{Referências}

AMRANI Younès, Stéphane BEAUD. Pays de malheur ! Un jeune de cité écrit à un sociologue. Paris : La Découverte, 2005.

BAUTIER Elisabeth. Mobilisation de soi, exigences langagières scolaires et processus de différenciation. Langage et société, nº111, p. 51-72, 2005.

BEAUD Stéphane. Le temps élastique. Étudiants des “cités" et examens universitaires. Terrain, n²9, p. 43-58, 1997.

BOURDIEU Pierre, Loïc WACQUANT. Réponses. Pour une anthropologie réflexive. Paris : Seuil, 1995 .

BOURDIEU Pierre, Jean-Claude PASSERON. Les Héritiers. Les étudiants et la culture. Paris : Minuit, 1964.

BOURDIEU Pierre, Jean-Claude PASSERON. La Reproduction. Éléments d'une théorie du système d'enseignement. Paris : Minuit, 1970.

BOURDIEU Pierre. Le sens pratique. Paris : Minuit, 1980.

BOURDIEU Pierre. Homo academicus, Paris : Minuit, $1984 a$.

BOURDIEU Pierre, Questions de sociologie. Paris : Minuit, 1984b.

BOURDIEU Pierre, Introduction à la socioanalyse. Actes de la recherche en sciences sociales, vol. 90, $n^{\circ} 1$, p. 3-5, 1991.

BOURDIEU Pierre. Esquisse pour une auto-analyse. Paris : Raisons d'agir, 2004.

CHAPOULIE Jean-Michel. Enseigner le travail de terrain et l'observation : témoignage sur une expérience (1970-1985). Genèses, n³ 39, p. 138-155, 2000.

DARMON Muriel. Devenir anorexique. Une approche sociologique. Paris : La Découverte, 2003. 
DARMON Muriel. La socialisation. Paris : Armand Colin, (128), 2006.

DARMON Muriel. Classes préparatoires. La fabrique d'une jeunesse dominante. Paris : La Découverte, 2013.

DONNAT Olivier. Les pratiques culturelles des français à l'heure du numérique. Enquête 2008. Paris : La Découverte, 2010.

EHRENBERG Alain. La fatigue d'être soi. Dépression et société. Paris : Odile Jacob, 1998.

GADEA Charles, Charles SOULIE. Réflexions sur une expérience d'initiation à la recherche en sociologie à l'Université (1994-2000). Genèses, nº 39 (2), p. 155-171, 2000.

GARCIA Sandrine. L'expert et le profane : qui est juge de la qualité universitaire?. Genèses, $n^{\circ} 70$ (1), p. 66-87, 2008.

JOUNIN Nicolas, Voyage de classes. Des étudiants de Seine-Saint-Denis enquêtent dans les beaux quartiers. Paris : La Découverte, 2014.

LAHIRE Bernard. Pour la sociologie. Et pour en finir avec une prétendue « culture de l'excuse ». Paris : La Découverte, 2016.

MUEL DREYFUS Francine. Le métier d'éducateur. Paris : Minuit, 1983.

POLIAK Claude. Manières profanes de «parler de soi, Genèses, n47 (2), p. 4-20.

SOULIÉ Charles. L'adaptation aux « nouveaux publics » de l'enseignement supérieur : auto-analyse d'une pratique d'enseignement magistral en sociologie, Sociétés contemporaines, $n^{\circ} 48$ (4), 2002, p. 11-39.

THIN Daniel. Quartiers populaires. L'école et les familles. Lyon : Presses universitaires de Lyon, 1998.

Recebido em: 07/03/2020

Aprovado em: 19/03/2020

Universidade do Estado de Santa Catarina - UDESC Programa de Pós-Graduação em Educação - PPGE

Revista Linhas

Volume 21 - Número 45 - Ano 2020

revistalinhas@gmail.com 